\title{
The Lamprey Forebrain - Evolutionary Implications
}

\author{
Shreyas M. Suryanarayana ${ }^{a, b}$ Juan Pérez-Fernández ${ }^{a, c}$ Brita Robertson $^{a}$ \\ Sten Grillner ${ }^{a}$ \\ ${ }^{a}$ Department of Neuroscience, Karolinska Institutet, Solna, Sweden; ${ }^{b}$ Department of Neurobiology, Duke University \\ Medical Center, Durham, NC, USA; ' CINBIO, Universidade de Vigo, Campus Universitario Lagoas, Vigo, Spain
}

\section{Keywords \\ Lamprey $\cdot$ Cortex $\cdot$ Basal ganglia $\cdot$ Thalamus $\cdot$ Habenula . \\ Evolution $\cdot$ Common ancestry $\cdot$ Forebrain $\cdot$ Vertebrates}

\begin{abstract}
The forebrain plays a critical role in a broad range of neural processes encompassing sensory integration and initiation/ selection of behaviour. The forebrain functions through an interaction between different cortical areas, the thalamus, the basal ganglia with the dopamine system, and the habenulae. The ambition here is to compare the mammalian forebrain with that of the lamprey representing the oldest now living group of vertebrates, by a review of earlier studies. We show that the lamprey dorsal pallium has a motor, a somatosensory, and a visual area with retinotopic representation. The lamprey pallium was previously thought to be largely olfactory. There is also a detailed similarity between the lamprey and mammals with regard to other forebrain structures like the basal ganglia in which the general organisation, connectivity, transmitters and their receptors, neuropeptides, and expression of ion channels are virtually identical. These initially unexpected results allow for the possibility that many aspects of the basic design of the vertebrate
\end{abstract}

karger@karger.com www.karger.com/bbe

Karger"
(C) 2021 The Author(s)

Published by S. Karger AG, Basel

This is an Open Access article licensed under the Creative Commons Attribution-NonCommercial-4.0 International License (CC BY-NC) (http://www.karger.com/Services/OpenAccessLicense), applicable to the online version of the article only. Usage and distribution for commercial purposes requires written permission. forebrain had evolved before the lamprey diverged from the evolutionary line leading to mammals. Based on a detailed comparison between the mammalian forebrain and that of the lamprey and with due consideration of data from other vertebrate groups, we propose a compelling account of a pan-vertebrate schema for basic forebrain structures, suggesting a common ancestry of over half a billion years of vertebrate evolution.

(c) 2021 The Author(s)

Published by S. Karger AG, Basel

\section{Introduction}

In this homage to the contributions of Luis Puelles and Agustin González, we will discuss recent data on the lamprey forebrain including the pallium (cortex), thalamus, basal ganglia, habenula, and the dopamine system. With a privileged position phylogenetically, the lamprey presents itself as a remarkable ancient vertebrate, belonging to the oldest group of now living vertebrates that diverged from the evolutionary line leading to mammals around 500 million years ago [Kumar and Hedges, 1998]. It has become apparent that these different parts of the lamprey forebrain are remarkably similar to those of 
their mammalian counterparts, although with much fewer nerve cells in each structure. The similarity applies to the overall organisation, connectivity, transmitters, expression of ion channels, and synaptic properties [Stephenson-Jones et al., 2011, 2012a, b, 2013; Ericsson et al., 2011, 2013a, b; Robertson et al., 2012; Pérez-Fernández et al., 2014, 2017; Ocaña et al., 2015; Grillner and Robertson, 2016; Suryanarayana et al., 2017, 2020, 2021], and we will review the evidence below and suggest that many aspects of the mammalian forebrain had evolved already before the lamprey and the mammalian lineage became separate.

\section{Pallium}

The cortical homologue in the lamprey, the pallium, had been considered for a long time to be largely olfactory with little or no representation of non-olfactory modalities [Northcutt and Wicht, 1997; Daghfous et al., 2018]. The evolutionary relationship of the pallium with that of the mammalian cortex was also virtually unknown, other than it being identified as the anatomical homologue with some suggestions of its subdivisions [Northcutt and Wicht, 1997; Nieuwenhuys and Nicolson, 1998]. One can identify two main anatomical subdivisions of the lamprey pallium - the medial pallium and the lateral part of pallium that we here will refer to as pallium. The medial pallium was suggested to be the anatomical homologue of the hippocampus while the pallium was thought to represent the cortex [Nieuwenhuys, 1977; Northcutt and Wicht, 1997]. Below we will show that the dorsal part of pallium contains a motor, a visual, and a somatosensory area, whereas the ventral part of pallium contains an olfactory area similar to the piriform cortex.

\section{Role of Pallium in Motor Control and Its Efferent Downstream Connectivity}

Our foray into the pallium began with the question of whether it had any role in generation of movements. In mammals including man, it has been well established that the motor areas of cortex can elicit different types of movements of the head and body [Georgopoulos and Grillner, 1989; Lemon, 2008, 2019] in response to electrical stimulations [Penfield and Boldrey, 1937]. Our extracellular low-threshold electrical stimulations of the lamprey pallium/cortex resulted in well-delineated movements of the eyes, neck, and mouth, as well as locomotion (Fig. 1a-e). These motor areas are localised to the caudolateral part of the pallium/cortex, identified as a "mo- tor pallium" (see heatmaps) [Ocaña et al., 2015; Suryanarayana et al., 2020]. Different properties of the elicited movements including amplitude, latency, and duration are dependent on stimulus parameters. The clear involvement of the pallium in motor behaviour led us to examine its efferent connectivity and whether the different movements generated were due to monosynaptic glutamatergic projections, which is a typical aspect of efferent mammalian neocortical control [Drew et al., 2004; Lemon, 2008, 2019]. The pallium/cortex has efferent projections to all downstream motor centres, including the striatum, subthalamic nucleus (STN), thalamus, deep layer of optic tectum, mesencephalic tegmentum, reticulospinal neurons, and interestingly, with some fibres also observed at the level of the rostral spinal cord (Fig. 1f). These efferent projections largely target the same areas as the equivalent projection neurons (layer $5 \mathrm{~b}$ ) in the mammalian neocortex. A major feature of the efferent glutamatergic projections of the mammalian neocortex are the two major subdivisions - the "PT-type" or pyramidal tract/extratelencephalic projections, which target the different downstream motor centres, and the "ITtype" with intratelencephalic projections, which cross through the corpus callosum to target the contralateral cortex and striatum [Reiner et al., 2010; Suárez et al., 2014; Kim et al., 2015]. The lamprey pallium/cortex also has these two types of projections - the PT-type projections target the ipsilateral striatum and downstream motor centres, while the IT-type cells target the ipsilateral and contralateral striatum and contralateral pallium with the fibres crossing in the habenular commissure (Fig. 1g) [Ocaña et al., 2015; Suryanarayana et al., 2020]. The PTtype projections to the optic tectum and the reticulospinal neurons are monosynaptic and glutamatergic [Ocaña et al., 2015].

The neocortex has been described as a "broadcaster" of motor command signals, which can utilise the subcortical motor infrastructure to generate and mediate goaldirected behaviours [Arber and Costa, 2018]. Our data with similar efferent connectivity in the lamprey pallium/ cortex suggests that this is an ancestral architecture and that during evolution, this design has been maintained. Pallial projections to downstream motor centres have also been mapped in non-mammalian amniotes including reptiles and avians [Hall et al., 1977; Dugas-Ford and Ragsdale, 2015], as well as in anamniotes, as for instance in sharks, in which pallial projections to the spinal cord have been observed [Ebbesson and Schroeder, 1971]. These data further support the common ancestry of the cortical efferent projection pattern. 
a

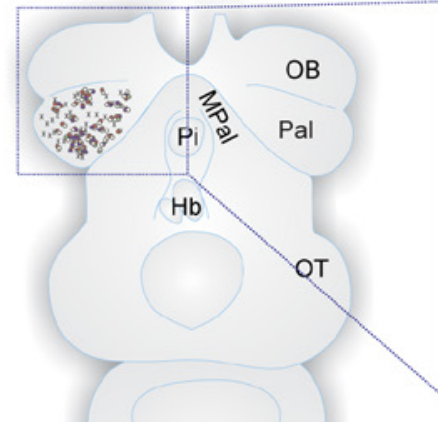

$\mathrm{Rh}$

f

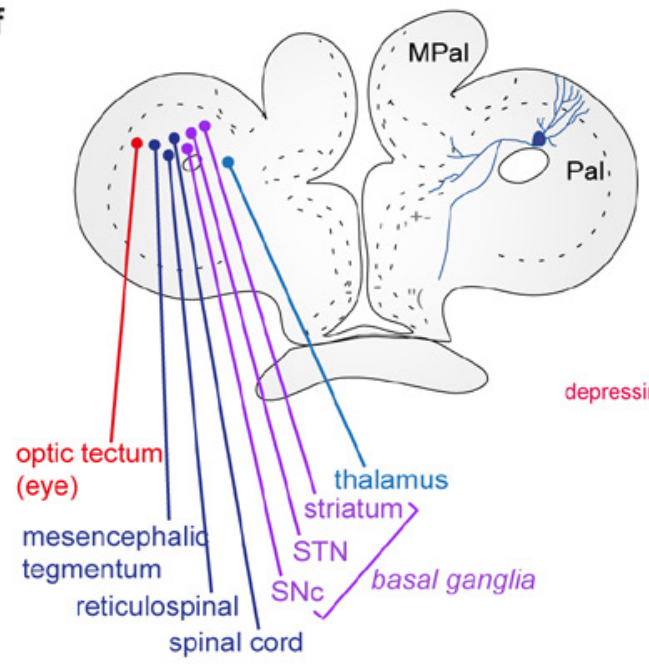

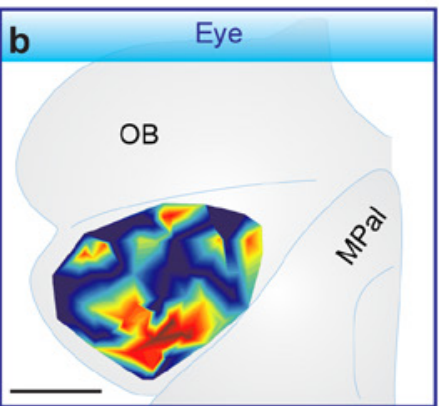

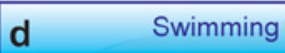

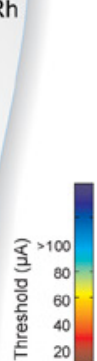
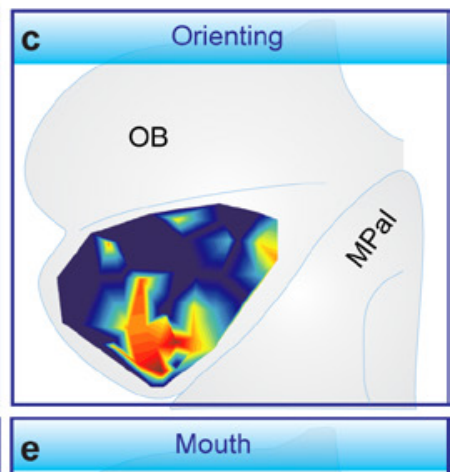

e

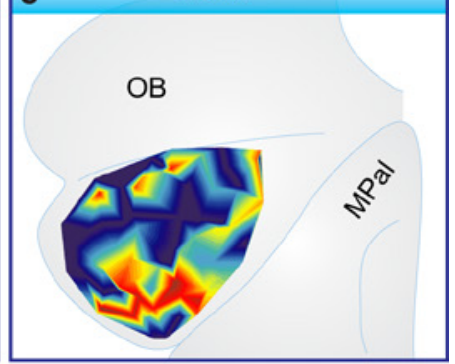

g

Fig. 1. The lamprey motor pallium. a Dorsal schematic view of the lamprey brain showing the distribution of electrical stimulation sites, which evoked different motor responses. b-e Heat maps representing the threshold current needed to evoke different motor behaviours. Note that the excitability decreases from the caudal to the rostral pallial pole. $\mathbf{f}$ Schematic of a transverse section of the lamprey pallium indicating the efferent targets of pallial projection neurons (PT-type). g The pallial/cortical axons that target the brainstem and spinal cord (PT-type) give off collaterals to neurons within the striatum. There is a subset of pallial neurons that have intratelencephalic axons projecting to the contralateral pallium/ cortex (IT-type) that also target the striatum. 


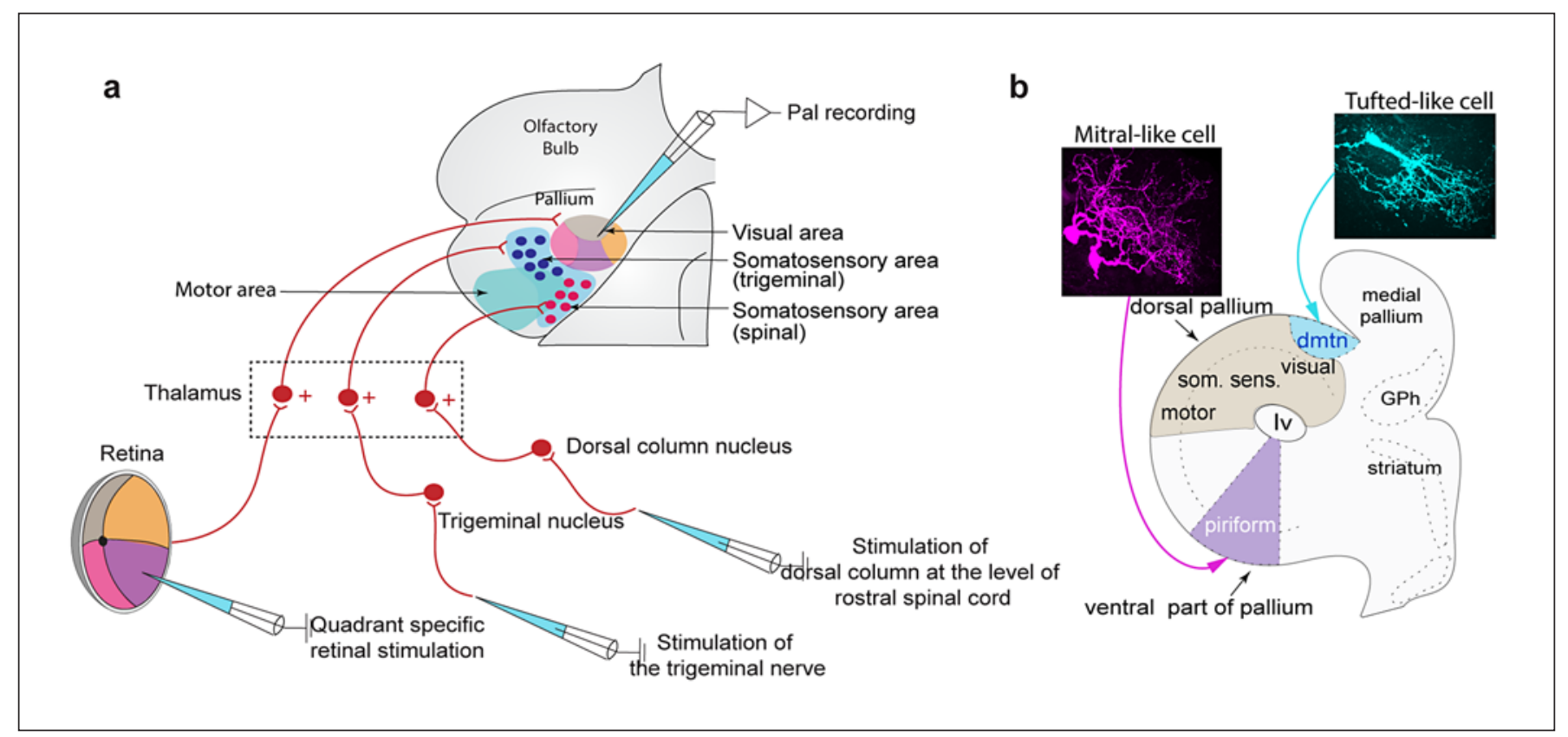

Fig. 2. Sensory representation in the lamprey pallium/cortex. a Summarising schematic of the lamprey dorsal pallium, showing retinotopic visual areas, somatosensory areas, and motor areas, as well as the retinal, trigeminal, and dorsal column nucleus afferents relayed via distinct subpopulations of thalamic neurons. $\mathbf{b}$ The olfactory system in lamprey resembles that of mammals in many

\section{Visual and Somatosensory Topography in the Dorsal Pallium}

In addition to the motor area in the lamprey pallium/ cortex, there are distinct visual and somatosensory areas. These areas were located in the dorsal parts of the pallium/cortex, the dorsal pallium (Fig. 2a) [Suryanarayana et al., 2020]. The visual area is retinotopically organised with stimulation of a specific quadrant of the retina eliciting response from a specific point within the visual area. The retinotopy is hardwired and maintained via the thalamic relay [Suryanarayana et al., 2020]. The somatosensory input is organised with distinct representations of the head and body - a basic somatotopy in the somatosensory area of the dorsal pallium, which is distinct from the visual and motor areas (Fig. 2a). Stimulations of the dorsal column in the spinal cord and the trigeminal sensory nerve elicit responses in different loci within the somatosensory area [Suryanarayana et al., 2020].

Distinct topographic visual, somatosensory, and motor areas are a hallmark of neocortical organisation in mammals and has been demonstrated in all mammals examined [Kaas, 2013; Raghanti et al., 2017; Briscoe and Ragsdale, 2019]. The order from visual to motor is the respects with a dual efferent system conveyed via tufted- and mitral-like cells. The latter target the olfactory cortex located in the ventral pallium, whereas the former target a separate limited region, the dorsomedial telencephalic nucleus (dmtn). Note the different morphology of the mitral-like (magenta) and tufted-like (blue) cells. same sequence as in mammals, but in the lamprey case the visual is medial and the motor in a more lateral position. It is conceivable that the overall relative topology of the sensory and motor areas of the lamprey dorsal pallium could be accounted for by a differential growth of pallium during evolution. There are also distinct representations of vision and somatosensation in the dorsal cortex of reptiles and in the avian Wulst, although the visual cortex in reptiles (turtle) has been reported not to be retinotopically organised [Dugas-Ford and Ragsdale, 2015; Fournier et al., 2018; Briscoe and Ragsdale, 2019]. The presence of a similar organisation in mammals, reptiles, and lamprey gives rise to the compelling possibility of this being an ancestral and conserved aspect of dorsal pallial organisation across vertebrates. This also overturns the long-held notion that the anamniote pallia are largely olfactory [Northcutt and Wicht, 1997; Wicht and Northcutt, 1998; Northcutt, 2011]. Furthermore, the sensory streams of somatosensory information, both trigeminal and spinal, are relayed to thalamus via the trigeminal sensory nucleus and the dorsal column nucleus, respectively. Retinal afferents target the thalamus directly, as shown earlier [Heier, 1948; Kennedy and Rubinson, 1977] but 
also indirectly via the optic tectum [Capantini et al., 2017]. Thus, the thalamus is an important relay of multimodal sensory input to the cortex in lamprey as in other vertebrates [Sherman and Guillery, 1996; Suryanarayana et al., 2020]. The overall evidence suggests that distinct and topographic representation of sensory modalities are a hallmark of the dorsal pallial organisation. With respect to visual input, retinotopic topography is maintained at three levels in the lamprey brain - the pallium, thalamus, and tectum, which is also true in mammals [Jones et al., 2009; Suryanarayana et al., 2020].

\section{Olfactory Representation in the Ventral Pallium}

Another major source of sensory input to the lamprey pallium/cortex is olfaction and for a long time, the entire pallium was thought of as largely olfactory [Northcutt and Puzdrowski, 1988]. The main olfactory system in lamprey has two discrete afferent systems as in mammals [Shepherd, 1972, 2004; Igarashi et al., 2012] - the mitraland the tufted-like cells, which have distinct terminations in the forebrain. The mitral-like cells, via the lateral olfactory tract, target the medial, ventral part of pallium, which forms the olfactory cortex, corresponding to the piriform cortex of mammals (Fig. 2b) [Igarashi et al., 2012]. In fact, early anatomical studies had suggested that the ventral part of pallium in lamprey corresponds to the primordial piriform cortex [Heier, 1948; Polenova and Vesselkin, 1993; Nieuwenhuys and Nicolson, 1998].

The other subgroup, the smaller tufted-like cells, project separately and exclusively to a relay nucleus called the dorsomedial telencephalic nucleus, which is located at the interface between the olfactory bulb and pallium (Fig. 2b). The dorsomedial telencephalic nucleus in turn projects to a circumscribed area in the anteromedial olfactory cortex. The lamprey olfactory cortex in the ventral pallium is activated with a short latency upon olfactory nerve stimulation, is three-layered similar to that of mammals, and has neurons with layer-spanning spiny dendrites [Suryanarayana et al., 2017]. In addition, this area relays information to the dorsal pallium wherein the dorsal pallial neurons may integrate the olfactory inputs and those from non-olfactory modalities [Suryanarayana et al., 2017].

It thus appears that visual, somatosensory, and motor areas in the dorsal pallium and olfactory representation in the ventral pallium are a general and common schema of vertebrate pallial organisation. One must also consider here evidence of distinct developmental sectors - the dorsal, medial, lateral, and ventral pallium [Puelles et al., 2019]. The four divisions have been identified in the developing pallia of avians and non-avian reptiles, as well as mammals [Puelles, 2017; Watson and Puelles, 2017]. Molecular evidence suggests that pallial and subpallial divisions and at least two pallial developmental sectors, the dorsal and ventral pallium, are present in cyclostomes [Sugahara et al., 2016, 2017]. Overall, the evidence pushes back the ancestry of pallial sectors to the dawn of vertebrate evolution [Puelles, 2019].

\section{Cytoarchitecture, Cell Types, and Microcircuit}

A distinct feature of the mammalian pallium is the presence of laminated structures. The neocortex has a sixlayered laminated architecture in its sensory areas but also granular areas.

The mammalian pallium, however, also includes three-layered structures like the piriform cortex and the hippocampus. The dorsal cortex of non-avian reptiles is also a three-layered structure. The lamprey pallium/cortex is similarly three-layered, with an outer molecular layer largely devoid of neurons and a cellular layer, which can be subdivided into two parts based on the relative distribution of GABAergic neurons and general cell density (Fig. 3a, e). The "inner cellular layer" consists of a higher proportion of GABAergic cells and an "outer cellular layer" with a smaller proportion of GABAergic cells but a higher cell density than the inner cell layer (Fig. 3ac). The overall proportion of GABAergic neurons in pallium is about $22 \%$ (Fig. $3 \mathrm{~d}$, e), which is roughly the same proportion as in mammals. With regard to GABAergic interneurons, calbindin- and calretinin-expressing interneurons are present.

The morphology of the pallium/cortex excitatory neurons resemble their pyramidal neuron counterparts in that their dendrites are spiny and layer spanning, extending to the outer molecular layer. These neurons generally possess two but sometimes one dendrite extending to the molecular layer (Fig. 3f). While the typical pyramidal neuron has an apical dendrite and basal dendrites [DeFelipe and Fariñas, 1992], the pallial/cortical neurons lack basal dendrites, and this is perhaps compensated by the second layer spanning dendrite and the rich ramifications. The morphology of the pallial excitatory neurons is similar to the morphology seen in the pyramidal neurons of the dorsal and lateral cortices of reptiles, which also typically have two main dendrites [Ulinski, 1990]. The excitatory neurons (PT, IT, and thalamorecipient types) [Suryanarayana et al., 2017] revealed two classical cortical firing properties - regular and burst firing (Fig. 3g, h).

With regards to sensory input to the pallial microcircuit (Fig. 4) [Suryanarayana et al., 2017], the thalamic input reaches the PT-type cells polysynaptically, via both 

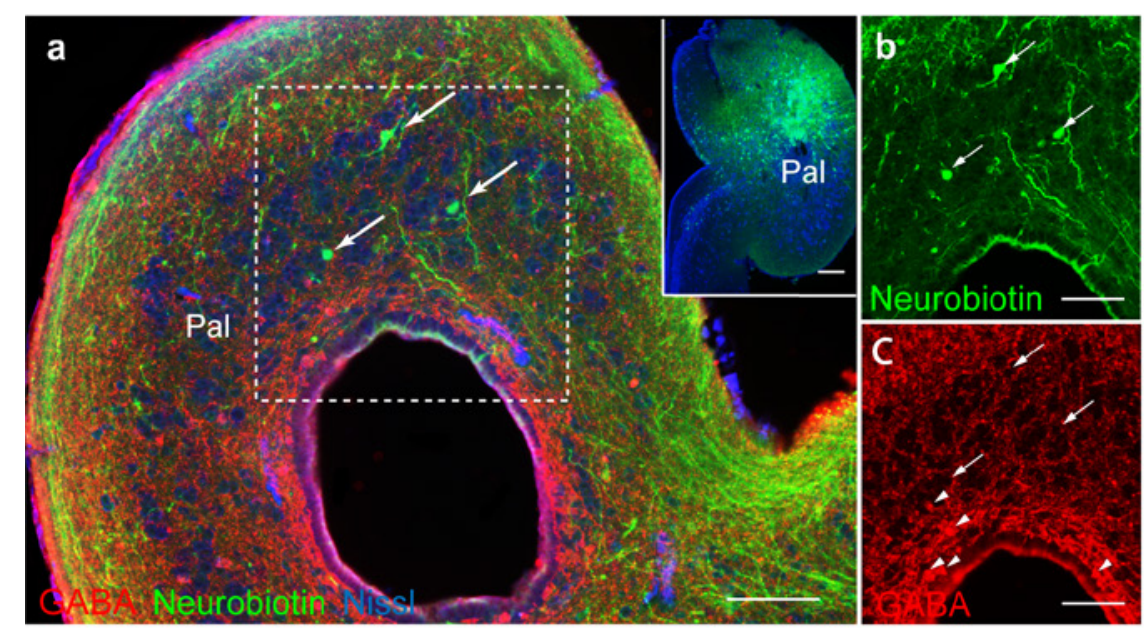

d

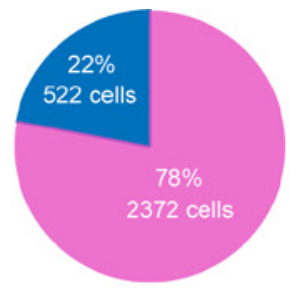

Inhibitory, excitatory

e
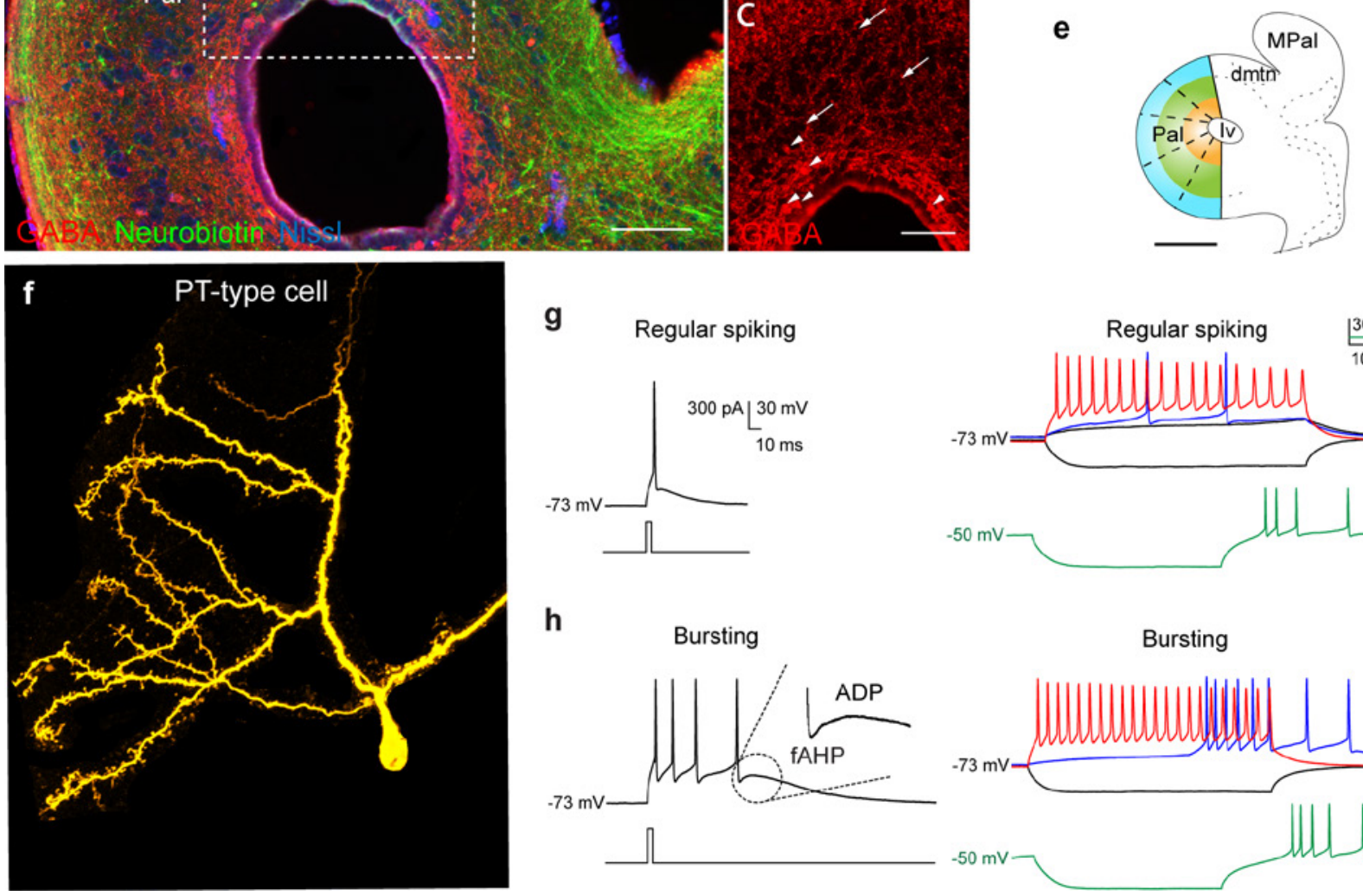

g

Regular spiking
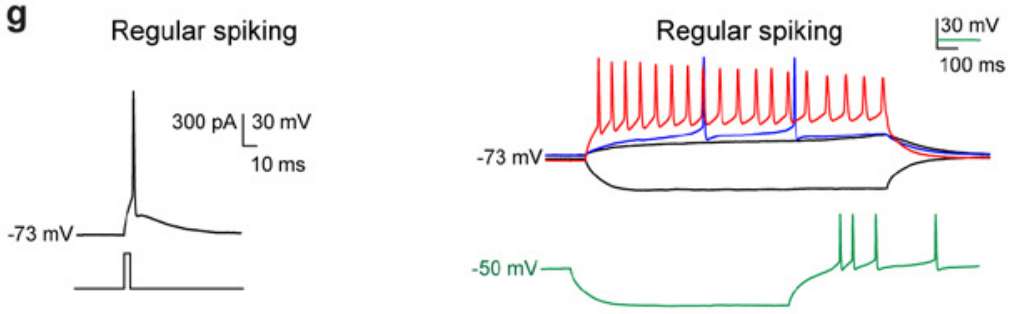

h

Bursting

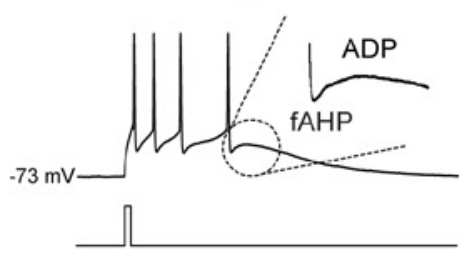

Bursting

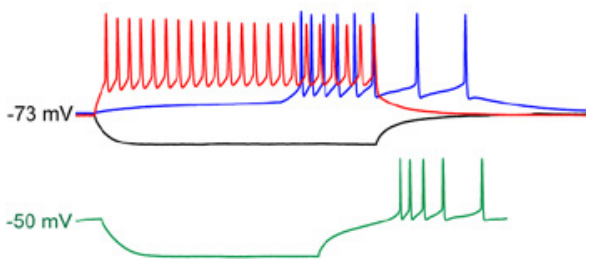

Fig. 3. Cell types in the lamprey pallium/cortex. a Retrogradely labelled IT-type cells (arrows) following Neurobiotin injection in the contralateral pallium (inset). b, c The IT-type cells (b, arrows) from the region of dotted square in a do not express GABA (c, arrowheads). d Overall percentage and number of GABAergic and non-GABAergic pallial neurons. e Schematic of the lamprey pallium with segments, indicated with dotted lines, used for cell counting. f Morphology of a PT-type cell showing spiny dendrites. g Firing properties of PT-type "regular spiking" cells with spiking due to a 5-ms suprathreshold current injection (left). Spiking due to $1 \mathrm{~s}$ depolarising current steps is also shown, with threshold response (blue) and maximal firing rate (red, right). Membrane po-

excitatory and inhibitory intercalated cells. Cells which receive monosynaptic thalamic input are the thalamorecipient cells. The thalamic input is glutamatergic and mediated by NMDA and AMPA receptors and the thalamic tential response to a 1-s hyperpolarising current step is also shown (black, right). Postinhibitory rebound spiking for a hyperpolarising current step from more depolarised membrane potentials (green). h Firing properties of PT-type "bursting" cells. Burst response to a 5-ms current injection is shown. Inset shows distinct afterpolarisation components: fAHP and ADP (left). Suprathreshold response for $1 \mathrm{~s}$ depolarising and hyperpolarising pulses with threshold and maximal firing (blue and red, respectively), as well as postinhibitory rebound spiking for a hyperpolarising current step from more depolarised membrane potentials (green) are shown (right). 
Fig. 4. The pallial microcircuit in the lamprey. The pallial microcircuit connectivity is shown with regard to pyramidal tract (PT), intratelecephalic (IT), and thalamorecipient (Thr) neurons with their sensory input from the retina via thalamus and from the olfactory bulb, as well as some efferent connections. Excitatory neurons are indicated in red and inhibitory interneurons in blue.

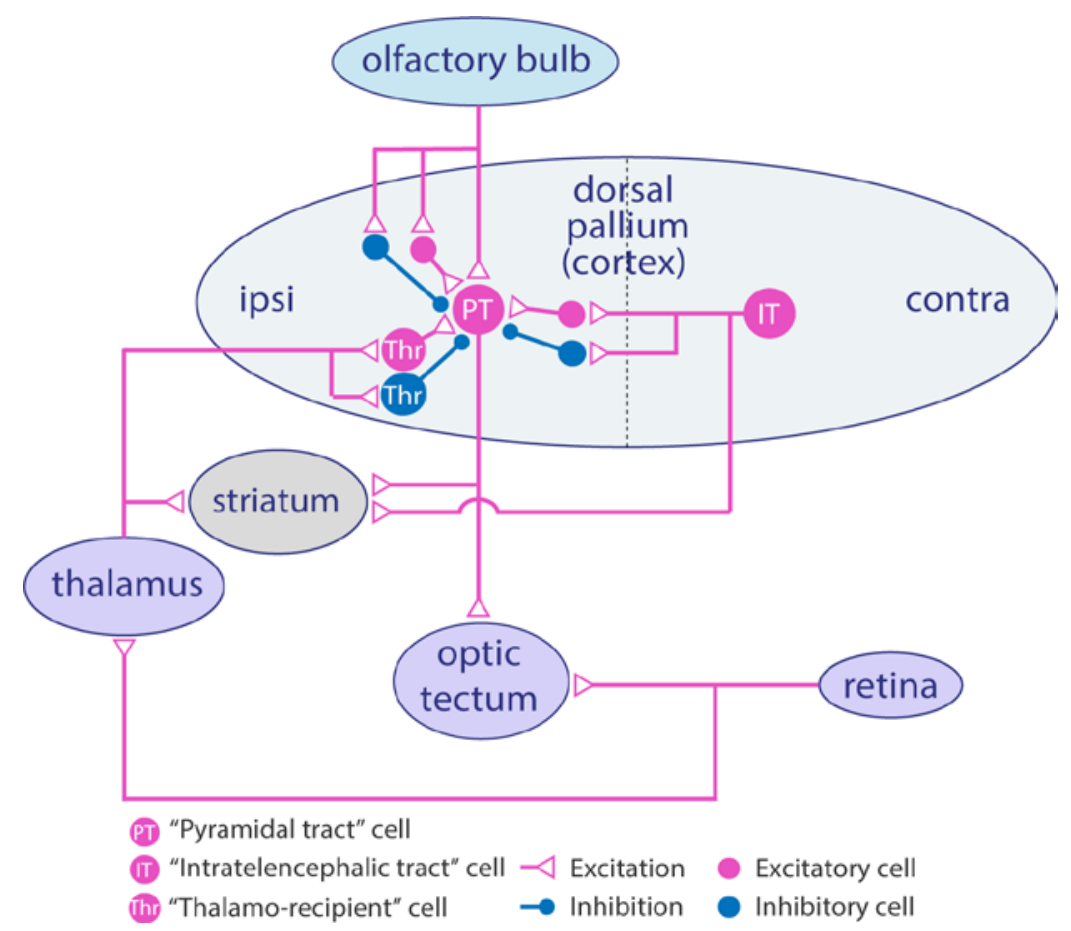

NMDA and AMPA receptors. It is relayed polysynaptically via intercalated excitatory and inhibitory neurons to the PT-type neurons.

The lamprey pallium/cortex has a basic input-output circuitry, which has been conserved in reptiles and mammals with PT, IT, and thalamorecipient neurons [Shepherd, 2011; Harris and Shepherd, 2015]. The excitatory neurons are located in the outer cellular layer while the number of GABAergic neurons is larger in the inner cellular layer, as in the three-layered dorsal cortex of reptiles [Ulinski, 1986, 1990]. Furthermore, the PT-type neurons in the pallium/cortex, the reptilian dorsal cortex, and the mammalian neocortex receive thalamic input polysynaptically [Shepherd, 2011]. The layer 4 neurons in the mammalian neocortex receive monosynaptic input, which is similar to thalamorecipient neurons in the lamprey pallium/cortex.

The mammalian neocortex has a plethora of cell types, both excitatory and inhibitory [Huang and Paul, 2019; Matho et al., 2020]. The major output cells, the layer 5b (PT-type) cells, which target the brainstem and spinal cord, are conserved from lamprey in terms of their projection pattern and function [Ocaña et al., 2015]. Similar output neurons are also found in the dor- sal pallial homologues in sauropsids. In addition, the ITtype cells are conserved in terms of their projection pattern targeting the contralateral pallium and striatum in the lamprey and reptiles. It has been proposed that also the ancestral reptile dorsal pallium had these three cell types (PT, IT, and thalamorecipient) [Briscoe and Ragsdale, 2019] and that this is a conserved feature of the dorsal pallium (see Fig. 7). This connectivity has been maintained from the lamprey and reptiles to mammals. However, there has been a conspicuous increase in the number of these cells during evolution and a dramatic generation of new excitatory cell types in mammals in terms of their molecular identity [Tosches and Laurent, 2019]. It is also interesting to consider that these cells appear to differ in their marker expression between different areas within neocortex itself - for instance between the visual cortex and the premotor cortex [Tasic et al., 2018]. It is conceivable that these new molecularly defined excitatory cell types have emerged from ancestral ones and this seems to be a fundamental principle of the evolution of the dorsal pallium across vertebrates. With regard to the inhibitory cell type, there seems to be a more robust conservation of the major classes of GABAergic interneurons in the reptile dorsal pallium when 


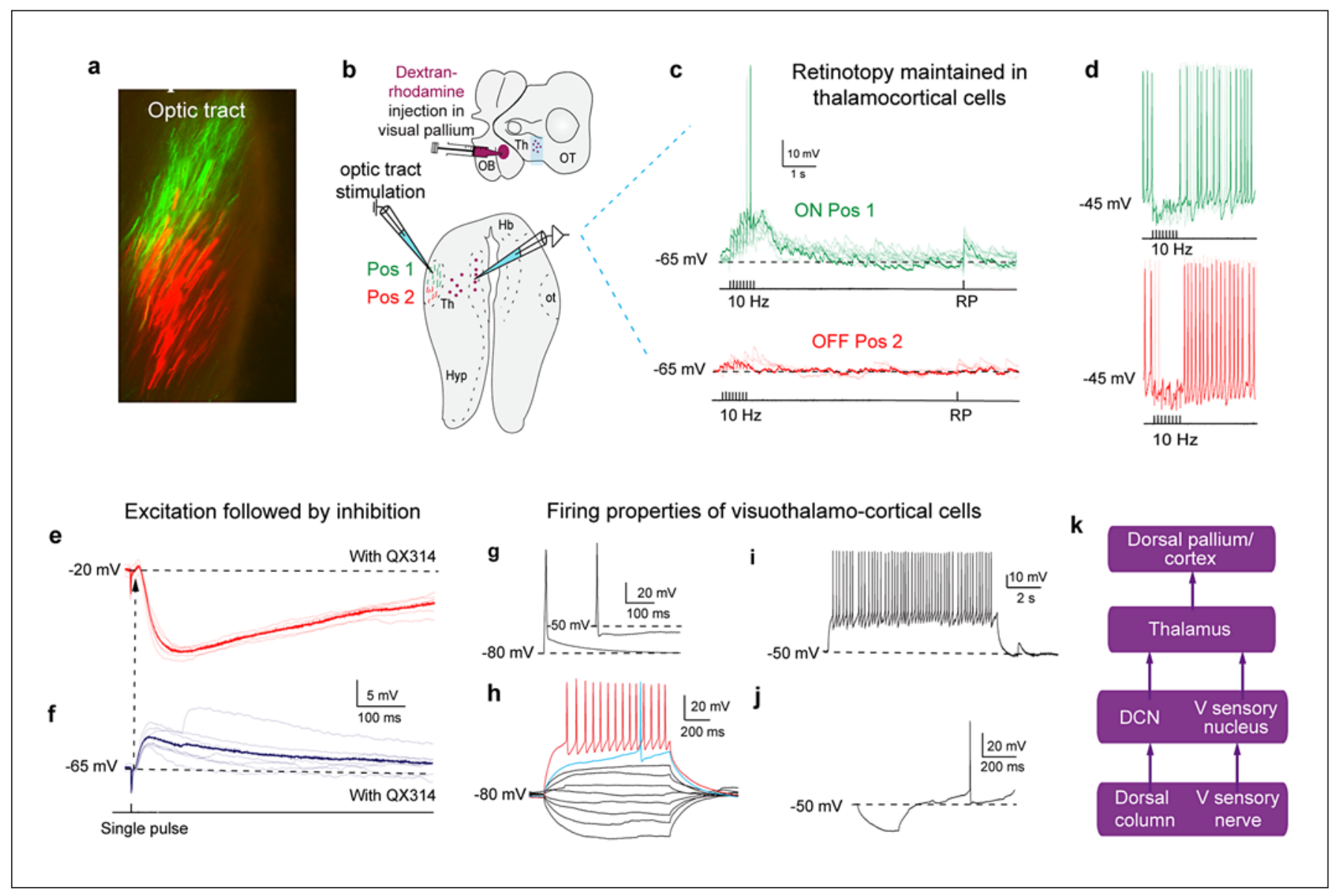

Fig. 5. The lamprey thalamus. a Retinotopic organisation in the optic tract following injections of dextran-rhodamine and dextran-FITCs into the caudal and rostral optic tectum, respectively. b Schematics showing injection of dextran-rhodamine to retrogradely prelabelled cells in the thalamus for recordings (upper panel) and site of stimulation and recording in the thalamus (lower panel). c Repetitive stimulation in one position of the optic tract elicits EPSPs/spiking (ON Pos 1) in a thalamopallial neuron, while another position provides very small EPSPs (OFF Pos 2). d Holding the cell at a more depolarised membrane potential elicits spiking, which is silenced by stimulation of both optic tract positions.

compared with the neocortex [Tosches et al., 2018]. In the lamprey, there are calbindin and calretinin immunoreactive neurons, while the presence of other major classes of interneurons remains unclear.

In summary, significant similarities are found at the microcircuit level including afferent inputs, connectivity, soma-dendritic morphology and physiology of constituent cell types in the lamprey pallium/cortex, the reptilian dorsal cortex, and the mammalian cortex suggesting a common ancestry of these features.

The Lamprey Forebrain e, $\mathbf{f}$ The onsets of single pulse EPSPs and IPSPs (arrow) show that excitation precedes inhibition. g Firing properties of thalamopallial neurons. Spikes were elicited in response to a brief $(5 \mathrm{~ms})$ suprathreshold current pulse, showing the afterhyperpolarisation. h Membrane potential responses to $1 \mathrm{~s}$ hyperpolarising and depolarising current pulses (step: $10 \mathrm{pA}$ ) showing threshold (blue trace) and suprathreshold response (red trace). i A long suprathreshold (10 s) pulse elicits non-adapting regular spiking behaviour. j A hyperpolarising pulse elicits postinhibitory rebound spiking. $\mathbf{k}$ Schematic showing thalamus as a relay of sensory information transmitted to pallium/cortex.

\section{Thalamus}

The thalamus is a key forebrain structure across vertebrates that contains relay nuclei for the different senses, but also higher order nuclei that relay for instance, preprocessed information from the tectum/superior colliculus [Jones, 2002; Sherman, 2016; Guillery, 2018]. In the lamprey, the thalamus can be divided into a periventricular zone of densely packed neurons and a lateral area of loosely arranged cells. The thalamopallial neurons are 
glutamatergic and located in both parts of the thalamus and are interspersed with GABAergic neurons [Pombal and Puelles, 1999; Villar-Cerviño et al., 2011; Suryanarayana et al., 2017, 2020].

The thalamus receives visual input from the retina and indirectly from tectum [Heier, 1948; Kennedy and Rubinson, 1977; Capantini et al., 2017]. Visual thalamopallial neurons extend their dendrites into the optic tract where synapses are formed [Suryanarayana et al., 2020]. In the optic tract the axons are arranged retinotopically and activate thalamopallial neurons maintaining the topography (Fig. 5a-d). Local GABAergic neurons are recruited by the visual input. While the excitatory thalamopallial neurons are activated from only one location of the optic tract, the GABA cells are activated from multiple locations and provide lateral inhibition (Fig. $5 c-f$ ). The somatosensory input from the body and head also reaches the thalamus from the dorsal column nucleus and the trigeminal sensory nucleus, respectively (Fig. 5k) [Suryanarayana et al., 2020, 2021]. Neurons in the periventricular area of thalamus target the striatum and its input is glutamatergic, depressing, drives intrastriatal inhibition, and is mediated by NMDA and AMPA receptors [Ericsson et al., 2013a]. Moreover, the thalamus receives input from the output nuclei of the basal ganglia [StephensonJones et al., 2011, 2012a]. Regarding the cellular properties of the thalamopallial neurons, they show an afterhyperpolarisation, tonic firing, and postinhibitory rebound spiking (Fig. 5g-j) as in other species.

The lamprey thalamus thus serves as a relay for sensory information to the pallium/cortex, but it also receives a major tectothalamic projection and input from the basal ganglia. It has a separate thalamostriatal projection. Hence, the main components of the mammalian thalamus are present already in the lamprey thalamus.

\section{Basal Ganglia, Habenula, and the Dopamine System}

We will consider three intertwined subpallial forebrain systems that are important for determining the control of action and which motor programs to be recruited, (1) the basal ganglia and (2) the dopamine system corresponding to substantia nigra pars compacta (SNc), which is critical for basal ganglia function, being activated by salient, rewarding, and aversive stimuli. Lastly, (3) the habenula, which consists of two separate parts with different functions, the lateral and medial habenulae. The lateral part controls the activity of dopamine neurons and other modulator systems and is considered to contribute to the evaluation of actions. The medial part is engaged in the control of fear responses like freezing and flight. We will discuss recent studies which show that these subpallial systems are conserved and that their basic organisation is very similar between the lamprey and mammals and most likely other vertebrate groups.

\section{The Basal Ganglia}

The circuit diagram of the lamprey basal ganglia is shown in Figure 6a, and it also applies to rodents [Stephenson-Jones et al., 2011, 2012a, 2013; Ericsson et al., 2011, 2013a, b; Robertson et al., 2012, Pérez-Fernández et al., 2014]. It consists of striatum, with input from the cortex and thalamus, a globus pallidus, an STN, and a substantia nigra pars reticulata ( $\mathrm{SNr})$. There is also a prominent input to striatum from dopamine neurons located in the SNc. These are the same compartments as in mammals, as shown in the scheme in Figure 6a. The output neurons of the basal ganglia in the $\mathrm{SNr}$ and globus pallidus interna (GPi) are GABAergic, tonically active under resting conditions, and they project to different motor centres to keep them under tonic inhibition. The striatal projection neurons (SPNs) are of two types. One that expresses dopamine receptors of the D1 type and substance $\mathrm{P}$, and projects directly to the $\mathrm{SNr}$. When activated, they will inhibit SNr neurons and thereby disinhibit the motor centres concerned downstream. These SPNs represent what is called the "direct pathway" and will promote action and they are referred to as dSPNs. The second type of SPNs express D2 receptors and enkephalin and project to cells in the globus pallidus externa (GPe), which in turn project to the glutamatergic STN. The net effect of an activation of D2-expressing SPNs is an enhanced activity in the $\mathrm{SNr}$, which leads to an enhanced inhibition of the downstream motor centres. The pathway from D2-SPNs is referred to as the "indirect pathway" and the SPNs as iSPNs. For some time, the developmental subpallial component which gives rise to the pallidum in mammals, the MGE, was thought to be absent in the lamprey. However, recent studies have demonstrated a Nkx2.1-positive MGE in the lamprey further adding evidence to the presence of a lamprey pallidum [Sugahara et al., 2016].

Figure $6 \mathrm{~b}$ provides a detailed comparison between the lamprey and the mammalian basal ganglia components and it brings out the striking resemblance between the two systems. On the input level it should be noted that the cortex in both groups acts through collaterals of pyramidal tract (PT) neurons projecting to brainstem motor centres and through the intratelencephalic (IT) neurons that target, apart from the contralateral pallium/cortex, 
a

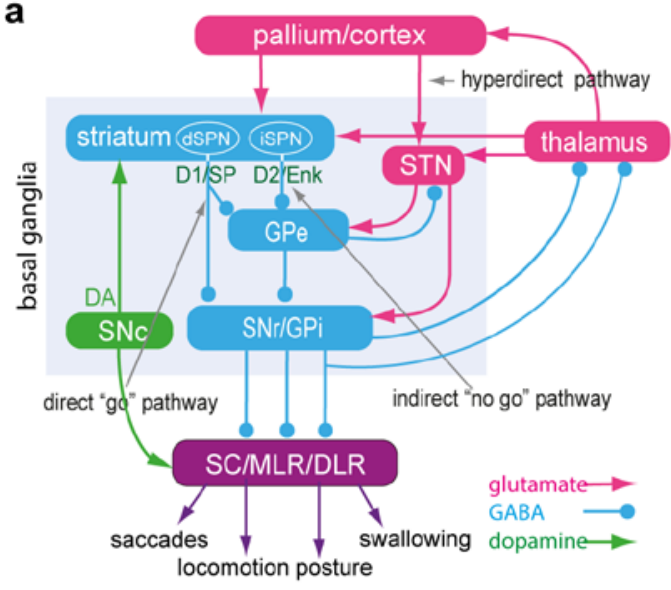

c

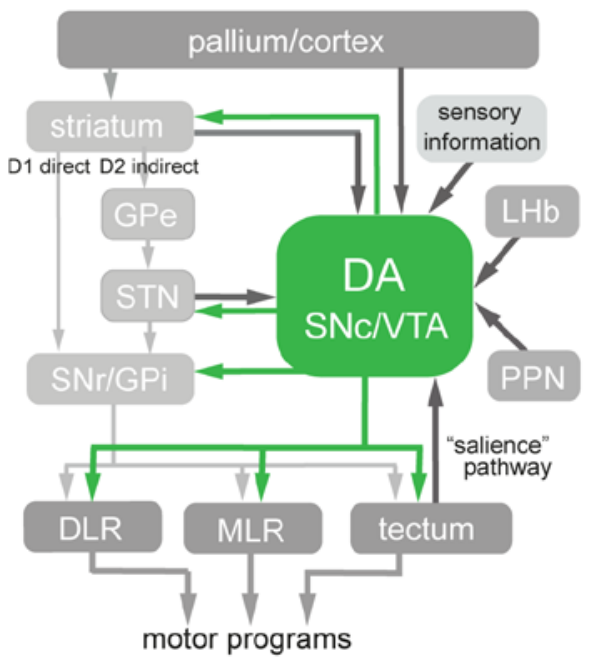

b

$\begin{array}{lcc} & \text { Lamprey } & \text { Mammals } \\ \text { Input to striatum } & & \\ \text { cortical IT-type } & + & + \\ \text { cortical PT-type } & + & + \\ \text { thalamus } & + & + \\ \text { dopamine } & + & + \\ \text { 5-HT } & + & + \\ \text { histamine } & + & + \\ \text { Striatal spiny projection neurons (SPN) } & \\ \text { D1R/SP } & + & + \\ \text { D2R/Enk } & + & + \\ \text { spiny dendrites } & + & + \\ \text { Kir } & + & + \\ \text { GABA } & + & + \\ \text { DARPP32 } & + & + \\ \text { rest hyperpol. } & + & + \\ \text { Striatal interneurons } & & \\ \text { cholinergic } & + & + \\ \text { fast spiking (FS) } & + & + \\ \text { subtypes of INs } & ? & +\end{array}$

Output pathway SNr/GPi

Lamprey Mammals

spontaneous activity direct input D1R/SP SPN GABA parvalbumin Indirect loop

$\mathrm{GPe}$

direct input from

D2R/Enk SPN

prototypical

arkypallidal

GABA

subthalamic nucleus

glutamate

spontanous activity

$\mathrm{I}_{\mathrm{h}}$

+
+
+
+
+
+
+
+
+
+

d

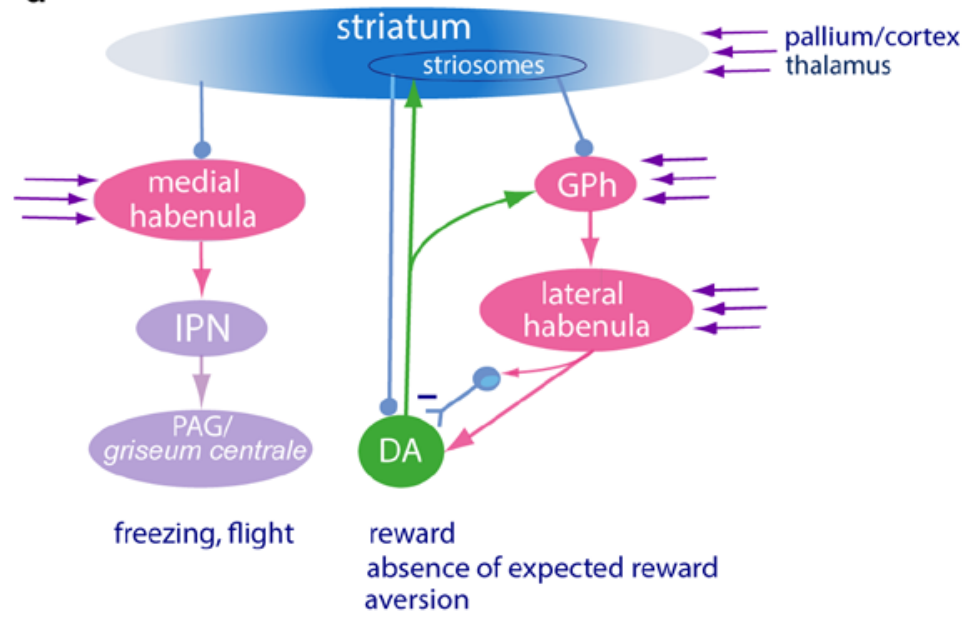

Fig. 6. The lamprey basal ganglia. a The organisation of the basal ganglia. The striatum consists of GABAergic neurons, as do GPe, $\mathrm{GPi}$, and SNr. SNr and GPi represent the output level of the basal ganglia, and it projects via different subpopulations of neurons to the tectum/superior colliculus, the mesencephalic, and diencephalic locomotor command regions and other brainstem motor centres, as well as back to thalamus with efference copies of information sent to the brainstem. The dSPNs that target SNr/GPi express the dopamine D1 receptor (D1) and substance $\mathrm{P}$ (SP), while the iSPNs express the dopamine D2 receptor (D2) and enkephalin (Enk). Also indicated is the dopamine input from the SNc (green) to striatum and brainstem centres. Excitatory glutamatergic neurons are shown in pink and GABAergic structures in blue colour. b A table showing the key features of the basal ganglia organisation that are found in mammals and the lamprey. c The SNc connectome in the lamprey and mammals. The efferent and afferent connectivity of the SNc is virtually identical. d The striatum targets both the medial and lateral habenulae. The medial habenula sends projections to the interpeduncular nucleus (IPN) and further to the periaqueductal grey (PAG)/griseum centrale. In mammals, PAG triggers a variety of fixed action patterns related to freezing and flight. The lateral habenula is engaged in the control of the different modulator systems and receives input from the glutamatergic part of globus pallidus (GPh), which in turn receives inhibition from the striosomal compartment of the striatum. The striosomes, $\mathrm{GPh}$, and the lateral habenula itself receive input from the pallium, thalamus, and other structures. 
only the ipsi- and contralateral striatum (see Fig. 1g). There are also the three modulator systems reaching the striatum - the dopamine, 5-HT, and histamine systems. SPNs are hyperpolarised during resting conditions and difficult to activate due to the expression of $\mathrm{K}_{\mathrm{ir}}$, a potassium channel open at rest, but closed when the membrane potential is depolarised. With regard to the interneurons in striatum, cholinergic and fast spiking interneurons exist in both groups, but whether the other subtypes present in mammals exist in lamprey is unknown. Both the direct and indirect pathways are present in both groups. The GPe neurons that iSPNs contact could correspond to the prototypical neurons. They in turn target the STN. Whether the newly discovered GPe neurons, called the arkypallidal neurons [Mallet et al., 2012], exist in lamprey is unknown. In rodents, these neurons project back to the striatum and have been referred to as "stop-cells". As in birds, the neurons of the lamprey GPe and GPi are intermingled, whereas in mammals they form two separate nuclei. All neurons within the GPe, GPi, and SNr are GABAergic and have spontaneous activity at rest, as do STN neurons.

Our data from the lamprey basal ganglia is based on a large number of studies combining neurophysiology, tracing studies, immunohistochemistry, and behaviour [Ericsson et al., 2011, 2013a, b; Stephenson-Jones et al., 2011, 2012a, 2013, Robertson et al., 2012, Pérez-Fernández et al., 2014]. These studies have unexpectedly revealed a very detailed similarity on all levels between the lamprey and mammals and strongly suggest that the basal ganglia had evolved very early in vertebrate evolution already when the lamprey lineage separated from that leading to mammals [Grillner and Robertson, 2016].

\section{The Dopamine System - Upstream and Downstream Control}

In the lamprey, dopamine neurons are present in several locations, like the olfactory bulb, SNc (located in the posterior tuberculum), hypothalamus, brainstem, and spinal cord [Schotland et al., 1995; Pierre et al., 1997; Pombal et al., 1997; Pérez-Fernández et al., 2014] and distribute their effects broadly (Fig. 6c). Dopamine neurons in the SNc send their processes to the striatum, STN, SNr, $\mathrm{GPi}$, motor centres in the tectum, and to the locomotor command centres in the diencephalon and mesencephalon (Fig. 6c) [Pombal et al., 1997; Robertson et al., 2012; Pérez-Fernández et al., 2014, 2017; Ryczko et al., 2013, 2017a, b, 2020]. The lamprey dopamine receptors located on dSPNs are of the D1 receptor subtype and provide de- polarisation, whereas the iSPNs expressing D2 receptors exert an inhibitory effect [Robertson et al., 2012; Ericsson et al., 2013b; Pérez-Fernández et al., 2014, 2017], the same effects as in mammals.

Dopamine neurons in the $\mathrm{SNc}$ receive input from a variety of sources and are activated by salient stimuli and presumably also in reward-related situations. Salient visual or electro-sensory stimuli activate the tectum, which in turn excites the dopamine neurons via direct projections in the lamprey, as well as in mammals [PérezFernández et al., 2014, 2017]. They are also under direct inhibitory control from SPNs in the striosome compartment of striatum (Fig. 6d) [Graybiel and Ragsdale, 1978]. In addition, they receive input from the lateral habenula (see below), which can exert a direct excitatory effect on the dopamine neurons in the $\mathrm{SNc}$, but also an inhibitory effect conveyed via a local GABAergic relay (Fig. 6d) [Stephenson-Jones et al., 2012b]. In addition, the pedunculopontine nucleus and pallium can activate $\mathrm{SNc}$ neurons. With regard to the pattern of input to $\mathrm{SNc}$ neurons and their output targets, the connectivity is virtually identical to that of the $\mathrm{SNc}$ in rodents and other mammals. The mammalian dopamine neurons in SNc are located primarily in the mesencephalon but extend into the diencephalon [Smeets et al., 2000; Wulliman, 2014], while the $\mathrm{SNc}$ in lamprey is located in the diencephalon. A diencephalic part of the dopamine innervation of striatum is present in all vertebrate groups [Wulliman, 2014; PérezFernández et al., 2014]. Coexpression of shh (sonic hedgehog) and TH (tyrosine hydoxylase) in posterior tubercular nuclei is a striking developmental parallel to the amniote mesodiencephalic dopamine cells of SN/VTA and supports homology of the teleostean posterior tubercular striatal projecting neurons with the diencephalic portion of the amniote SN/VTA [Wullimann and Umeasalugo, 2020]. The striking similarity between the innervation pattern and input between lamprey, zebrafish, and mammals and other vertebrate groups strongly suggest that they represent the same group of neurons [Pérez-Fernández et al., 2014] and that the dopaminergic neurons in the posterior tuberculum can be referred to as the lamprey SNc.

The effect of the dopaminergic downstream innervation of motor centres like the tectum [Pérez-Fernández et al., 2017] and MLR [Ryczko et al., 2013, 2017a, b, 2020] has been studied in considerable detail. In the lamprey, activation of the dopamine neurons in the $\mathrm{SNc}$ promotes the initiation of locomotion at the level of MLR, and a blockade of dopamine receptors increases the threshold for activation of locomotion. Also in other vertebrates, 
there is a facilitation of locomotion via the dopaminergic projections to MLR [Ryczko et al., 2013, 2017a, b, 2020]. In the lamprey as well as in mammals there are dopaminergic projections from the SNc to tectum/superior colliculus by collaterals of the axons that target striatum [Campbell and Takada, 1989; Pérez-Fernández et al., 2017; von Twickel et al., 2019]. Thus, each time there is a burst of activity in the dopamine neurons due to a salient stimulus, not only the striatum but also the tectum will be affected. The number of dopaminergic axonal terminals are dense in the deep tectal layer, where the output premotor neurons are located, while being sparse in the superficial sensory layer. The tectal output neurons express either D1 or D2 receptors [Robertson et al., 2012; PérezFernández et al., 2014, 2017]. Activation of the dopamine input affects the excitability of the tectal output neurons and is dependent on receptor subtype either in a facilitating or depressing direction. Visual looming or bar stimuli evokes eye or orienting/evasive trunk movements elicited via tectum [Suzuki et al., 2019]. They are markedly facilitated by dopamine. The dopamine innervation of tectum thus markedly affects the tectal circuitry responsible for eye and trunk movements.

As mentioned earlier, the same dopamine neuron sends axonal branches to both tectum and striatum, but it turns out that the two branches display different properties. The axonal branch to striatum co-expresses and co-releases glutamate and dopamine in the striatum, while the branch projecting to tectum does not contain glutamatergic vesicles and it releases only dopamine [von Twickel et al., 2019]. This presumably means that there is an interaction between the axon terminal and the target cells at the synapse that will determine whether glutamatergic vesicles will be formed or not.

The impact of the dopamine system on motor behaviour in the lamprey has been investigated by using the neurotoxin MPTP that kills the dopamine cells [Thompson et al., 2008]. After MPTP, the lampreys become very inactive and it is difficult to make them swim, and if at all they move, it will be a short bout of swimming. Moreover, they have rigidity remaining after any swimming episode and an increased reaction time. These are the same type of Parkinsonian symptoms that a dopamine-denervation gives rise to in other vertebrates, including primates and humans.

In conclusion, the dopamine system (SNc) of the lamprey and that of other vertebrates are very similar with regard to overall organisation, connectivity, cellular and synaptic properties, and the behavioural effects of dopamine.

The Lamprey Forebrain

\section{The Lateral and Medial Habenulae}

The medial and lateral habenulae are present throughout vertebrate phylogeny and located dorsal to thalamus in the diencephalon (epithalamus). The main connectivity of the lamprey lateral and medial habenulae are shown in Figure $6 \mathrm{~d}$. They are engaged in the control of the different modulator systems and in eliciting fear reactions, respectively.

The lateral habenula receives input from the glutamatergic part of globus pallidus (GPh), which in turn receives inhibition from the striosomal compartment of the striatum [Stephenson-Jones et al., 2012b, 2013, 2016]. The striosomes, GPh, and the lateral habenula themselves receive input from the pallium, thalamus, and other structures. As in primates and other vertebrates, the lateral habenula also receives input from the lateral hypothalamus [Proulx et al., 2014; Lazaridis et al., 2019]. Separate glutamatergic subpopulations within the lateral habenula control the activity of the dopamine neurons in $\mathrm{SNc}$, the 5-HT neurons in the mammillary area, and histaminergic neurons in the periventricular area of hypothalamus, all of which in turn provide important modulatory input to the striatum. Histaminergic neurons display circadian activity and affect the excitability of striatal neurons [Ellender et al., 2011].

The medial habenula receives relayed input from different senses, like olfaction from the olfactory bulb, light activating the pineal gland, and electrosensation and vestibular input mediated from the pretectum. There is also a direct input from the striatum. In mammals, there is in addition input from limbic structures that are absent in lamprey. The cholinergic projections of the medial habenula target the interpeduncular nucleus, which in turn projects to griseum centrale [Olson et al., 2017]. In zebrafish, the griseum centrale mediates freezing responses to cope with aversive responses [Okamoto et al., 2021]. The griseum centrale corresponds to the periaqueductal grey in mammals, which triggers a variety of fixed action patterns related to freezing, flight, and vocalisation [Subramanian et al., 2020].

In conclusion, the organisation of the input to the lateral habenula is similar to that of mammals, whereas the input to the medial habenula is related more directly to the different senses, while additionally in mammals, the septum and limbic structures provide the input. The organisation of the output from both the medial and lateral habenulae is similar in both vertebrate groups. The control of the different modulator systems and protective responses such as freezing are important contributions of the two habenulae. 


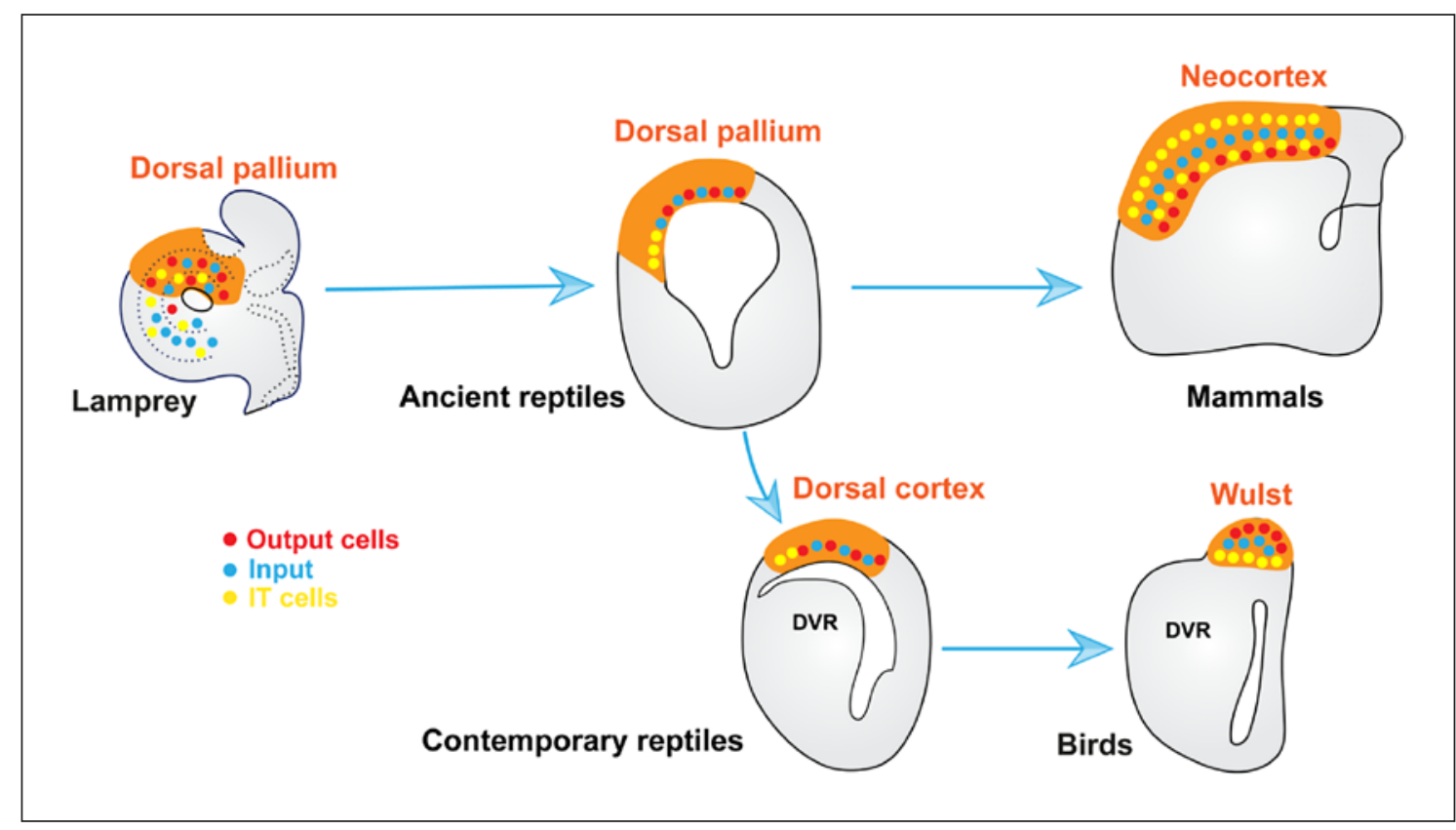

Fig. 7. Conceptual schema for cell type evolution in the dorsal pallium. Schematic of the pallium with dorsal pallial homologues (orange) with basic input-output and intratelencephalic cell types proposed in the lamprey (cyclostomes), the common reptilian ancestor, and in modern reptiles and mammals [Briscoe and Ragsdale, 2019; Suryanarayana, 2019].

\section{Similarities Suggest Conservation and Common Ancestry - The Vertebrate Forebrain}

A critical yardstick for evaluating homologous structures, similarities, signify an important evolutionary principle - conservation and common ancestry. As we have shown in considerable detail above, there are consistent and detailed similarities between the lamprey and mammals with regard to the basal ganglia, thalamus, the dorsal and ventral pallia in terms of organisation, connectivity, neurotransmitters, peptides, and ion channel expression. Similarly, the habenula, the SNc dopamine system also show a very high degree of conservation. It must be remembered that the lamprey (cyclostomes) and mammals represent two extreme phylogenetic groups in vertebrates, and any evolutionary conclusions will echo across vertebrate evolution. Much less information is available in other groups of anamniotes, but the fragments available are consistent with an evolutionary lineage through elasmobranchs, basic teleosts (holosteans, gar) and amphibians. More recent teleosts have evolved an additional relay structure between tectum and pallium/cortex [Bloch et al., 2020], which is not present in another vertebrates. Figure 7 illustrates schematically an evolutionary line from the dorsal pallium of lamprey to basal reptiles and mammals [Briscoe and Ragsdale, 2019; Suryanarayana, 2019; Suryanarayana et al., 2020]. Modern reptiles, have in addition developed the dorsoventricular ridge that is further developed in birds [Briscoe and Ragsdale, 2019]. When the entire forebrain is considered together, the data strongly supports our interpretation that fundamental aspects of the vertebrate forebrain design had evolved very early in vertebrate evolution, some 500 million years ago before the lamprey lineage became separate from that leading to mammals, and has been maintained notwithstanding the significant plasticity in forebrain structures seen across vertebrates [StephensonJones et al., 2012a; Grillner and Robertson, 2016; Briscoe and Ragsdale, 2019; Suryanarayana, 2019]. We conclude that there is a very high degree of detailed similarity at the molecular level (ion channels, transmitters, neuropeptides) and regarding connectivity, overall organisation within each of the systems discussed, and the interaction between these intertwined components of the forebrain. It is therefore not credible to assume that they could have evolved independently through convergence, but rather must be explained by conservation and common ancestry. We believe and propose that these commonalities present a common schema of forebrain organisation conserved across vertebrates. It must be noted here that de- 
tailed investigations of forebrain structures with modern techniques have not been undertaken in large groups of vertebrates, particularly in the vast anamniote lineage. More data from phylogenetically important basal species in different vertebrate clades will eventually help paint the full picture of vertebrate forebrain evolution.

\section{Conclusion}

In this review of the lamprey forebrain, we have shown that there is a remarkable similarity with the mammalian forebrain with regard to overall organisation, connectivity, transmitters, and cellular properties in dorsal and ventral pallium, thalamus, basal ganglia, the dopaminergic SNc, and the lateral and medial habenulae. We infer that the overall design of the vertebrate forebrain through evolution, must have taken place before the separation of the lamprey and the mammalian evolutionary lines.

\section{Conflict of Interest Statement}

The authors have no conflicts of interest to declare.

\section{Funding Sources}

The support of the Swedish Medical Research Council (VR-MK2013-62X-03026, VR-M-2015-02816, VR-M-2018-02453 and VR-M-2019-01854), EU/FP7 Moving Beyond grant ITNNo-316639, European Union Seventh Framework Programme (FP7/2007-2013) under grant agreement No. 604102 (HBP), EU/ Horizon 2020 No. 720270 (HBP SGA1), No. 785907 (HBP SGA2), and No. 945539 (HBP SGA3), Ramón y Cajal, Spain, RYC2018024053-I, and the Karolinska Institutet is gratefully acknowledged.

\section{Author Contributions}

S.G. and S.M.S. wrote the manuscript in interaction with B.R. and J.P.-F. All authors approved the final version of the manuscript.

\section{References}

Arber S, Costa RM. Connecting neuronal circuits for movement. Science. 2018 Jun;360(6396): $1403-4$.

Bloch S, Hagio H, Thomas M, Heuzé A, Hermel JM, Lasserre E, et al. Non-thalamic origin of zebrafish sensory nuclei implies convergent evolution of visual pathways in amniotes and teleosts. eLife. 2020 Sep;9:e54945.

Briscoe SD, Ragsdale CW. Evolution of the Chordate Telencephalon. Curr Biol. 2019 Jul; 29(13):R647-62.

Campbell KJ, Takada M. Bilateral tectal projection of single nigrostriatal dopamine cells in the rat. Neuroscience. 1989;33(2):311-21.

Capantini L, von Twickel A, Robertson B, Grillner $\mathrm{S}$. The pretectal connectome in lamprey. J Comp Neurol. 2017 Mar;525(4):753-72.

Daghfous G, Auclair F, Clotten F, Létourneau JL, Atallah E, Millette JP, et al. GABAergic modulation of olfactomotor transmission in lampreys. PLoS Biol. 2018 Oct;16(10):e2005512.

DeFelipe J, Fariñas I. The pyramidal neuron of the cerebral cortex: morphological and chemical characteristics of the synaptic inputs. Prog Neurobiol. 1992 Dec;39(6):563-607.

Drew T, Prentice S, Schepens B. Cortical and brainstem control of locomotion. Prog Brain Res. 2004;143:251-61.

Dugas-Ford J, Ragsdale CW. Levels of homology and the problem of neocortex. Annu Rev Neurosci. 2015 Jul;38(1):351-68.

Ebbesson SO, Schroeder DM. Connections of the nurse shark's telencephalon. Science. 1971 Jul;173(3993):254-6.
Ellender TJ, Huerta-Ocampo I, Deisseroth K, Capogna M, Bolam JP. Differential modulation of excitatory and inhibitory striatal synaptic transmission by histamine. J Neurosci. 2011 Oct;31(43):15340-51.

Ericsson J, Silberberg G, Robertson B, Wikström MA, Grillner S. Striatal cellular properties conserved from lampreys to mammals. J Physiol. 2011 Jun;589(Pt 12):2979-92.

Ericsson J, Stephenson-Jones M, Kardamakis A, Robertson B, Silberberg G, Grillner S. Evolutionarily conserved differences in pallial and thalamic short-term synaptic plasticity in striatum. J Physiol. 2013a Feb;591(4):859-74.

Ericsson J, Stephenson-Jones M, Pérez-Fernández J, Robertson B, Silberberg G, Grillner S. Dopamine differentially modulates the excitability of striatal neurons of the direct and indirect pathways in lamprey. J Neurosci. 2013b May;33(18):8045-54.

Fournier J, Müller CM, Schneider I, Laurent G. Spatial Information in a Non-retinotopic Visual Cortex. Neuron. 2018 Jan;97(1):164-180. e7.

Georgopoulos AP, Grillner S. Visuomotor coordination in reaching and locomotion. Science. 1989 Sep;245(4923):1209-10.

Graybiel AM, Ragsdale CW Jr. Histochemically distinct compartments in the striatum of human, monkeys, and cat demonstrated by acetylthiocholinesterase staining. Proc Natl Acad Sci USA. 1978 Nov;75(11):5723-6.

Grillner S, Robertson B. The Basal Ganglia Over 500 Million Years. Curr Biol. 2016 Oct; 26(20):R1088-100.
Guillery R. The Brain as a Tool. Oxford University Press; 2018.

Hall JA, Foster RE, Ebner FF, Hall WC. Visual cortex in a reptile, the turtle (Pseudemys scripta and Chrysemys picta). Brain Res. 1977 Jul;130(2):197-216.

Harris KD, Shepherd GM. The neocortical circuit: themes and variations. Nat Neurosci. 2015 Feb;18(2):170-81.

Heier P. Fundamental properies in the structure of the brain. A study of the brain of Petromyzon marinus. Acta Anat (Basel). 1948;8:3213

Huang ZJ, Paul A. The diversity of GABAergic neurons and neural communication elements. Nat Rev Neurosci. 2019Sep;20(9):56372.

Igarashi KM, Ieki N, An M, Yamaguchi $\mathrm{Y}$, Nagayama S, Kobayakawa K, et al. Parallel mitral and tufted cell pathways route distinct odor information to different targets in the olfactory cortex. J Neurosci. 2012 Jun;32(23): 7970-85.

Jones EG. Thalamic organization and function after Cajal. Prog Brain Res. 2002;136:333-57.

Jones MR, Grillner S, Robertson B. Selective projection patterns from subtypes of retinal ganglion cells to tectum and pretectum: distribution and relation to behavior. J Comp Neurol. 2009 Nov;517(3):257-75.

Kaas JH. The evolution of brains from early mammals to humans. Wiley Interdiscip Rev Cogn Sci. 2013 Jan;4(1):33-45. 
Kennedy MC, Rubinson K. Retinal projections in larval, transforming and adult sea lamprey, Petromyzon marinus. J Comp Neurol. 1977 Feb;171(4):465-79.

Kim EJ, Juavinett AL, Kyubwa EM, Jacobs MW, Callaway EM. Three Types of Cortical Layer 5 Neurons That Differ in Brain-wide Connectivity and Function. Neuron. 2015 Dec; 88(6):1253-67.

Kumar S, Hedges SB. A molecular timescale for vertebrate evolution. Nature. 1998 Apr; 392(6679):917-20.

Lazaridis I, Tzortzi $\mathrm{O}$, Weglage $\mathrm{M}$, Märtin A, Xuan Y, Parent M, et al. A hypothalamus-habenula circuit controls aversion. Mol Psychiatry. 2019 Sep;24(9):1351-68.

Lemon R. Recent advances in our understanding of the primate corticospinal system. F1000 Res. 2019 Mar;8:8.

Lemon RN. Descending pathways in motor control. Annu Rev Neurosci. 2008;31(1):195-218.

Mallet N, Micklem BR, Henny P, Brown MT, Williams C, Bolam JP, et al. Dichotomous organization of the external globus pallidus. Neuron. 2012 Jun;74(6):1075-86.

Matho KS, Huilgol D, Galbavy W, Kim G, He M, An X, et al. Genetic dissection of glutamatergic neuron subpopulations and developmental trajectories in the cerebral cortex. bioRxiv. 2020;2020.2004.2022.054064.

Nieuwenhuys R, Nicholson C. Lampreys (Petromyzontoidea). In: Nieuwenhuys R, Donkelaar HJ, Nicholson C, editors. The Central Nervous System of Vertebrates. Berlin, Heidelberg: Springer; 1998. pp. 397-495.

Nieuwenhuys R. The brain of the lamprey in a comparative perspective. Ann N Y Acad Sci. 1977 Sep;299 1 Evolution and:97-145.

Northcutt RG, Puzdrowski RL. Projections of the olfactory bulb and nervus terminalis in the silver lamprey. Brain Behav Evol. 1988;32(2):96107.

Northcutt RG, Wicht H. Afferent and efferent connections of the lateral and medial pallia of the silver lamprey. Brain Behav Evol. 1997, 49(1):1-19.

Northcutt RG. Do teleost fishes possess a homo$\log$ of mammalian isocortex? Brain Behav Evol. 2011;78(2):136-8.

Ocaña FM, Suryanarayana SM, Saitoh K, Kardamakis AA, Capantini L, Robertson B, et al. The lamprey pallium provides a blueprint of the mammalian motor projections from cortex. Curr Biol. 2015 Feb;25(4):413-23.

Okamoto H, Cherng BW, Nakajo H, Chou MY, Kinoshita M. Habenula as the experience-dependent controlling switchboard of behavior and attention in social conflict and learning. Curr Opin Neurobiol. 2021 Jan;68:36-43.

Olson I, Suryanarayana SM, Robertson B, Grillner S. Griseum centrale, a homologue of the periaqueductal gray in the lamprey. IBRO Rep. 2017 Jan;2:24-30.

Penfield W, Boldrey E. Somatic motor and sensory representation in the cerebral cortex of man as studied by electrical stimulation. Brain. 1937;60(4):389-443.
Pérez-Fernández J, Kardamakis AA, Suzuki DG, Robertson B, Grillner S. Direct Dopaminergic Projections from the SNc Modulate Visuomotor Transformation in the Lamprey Tectum. Neuron. 2017 Nov;96(4):910-924.e5.

Pérez-Fernández J, Stephenson-Jones M, Suryanarayana SM, Robertson B, Grillner S. Evolutionarily conserved organization of the dopaminergic system in lamprey: SNc/VTA afferent and efferent connectivity and D2 receptor expression. J Comp Neurol. 2014 Dec;522(17):3775-94.

Pierre J, Mahouche M, Suderevskaya EI, Repérant J, Ward R. Immunocytochemical localization of dopamine and its synthetic enzymes in the central nervous system of the lamprey Lampetra fluviatilis. J Comp Neurol. 1997 Mar; 380(1):119-35.

Polenova OA, Vesselkin NP. Olfactory and nonolfactory projections in the river lamprey (Lampetra fluviatilis) telencephalon. J Hirnforsch. 1993;34(2):261-79.

Pombal MA, El Manira A, Grillner S. Afferents of the lamprey striatum with special reference to the dopaminergic system: a combined tracing and immunohistochemical study. J Comp Neurol. 1997 Sep;386(1):71-91.

Pombal MA, Puelles L. Prosomeric map of the lamprey forebrain based on calretinin immunocytochemistry, Nissl stain, and ancillary markers. J Comp Neurol. 1999 Nov;414(3): 391-422.

Proulx CD, Hikosaka O, Malinow R. Reward processing by the lateral habenula in normal and depressive behaviors. Nat Neurosci. 2014 Sep;17(9):1146-52.

Puelles L, Alonso A, García-Calero E, Martínezde-la-Torre M. Concentric ring topology of mammalian cortical sectors and relevance for patterning studies. J Comp Neurol. 2019 Jul;527(10):1731-52.

Puelles L. Comments on the Updated Tetrapartite Pallium Model in the Mouse and Chick, Featuring a Homologous Claustro-Insular Complex. Brain Behav Evol. 2017;90(2):171-89.

Puelles L. Survey of Midbrain, Diencephalon, and Hypothalamus Neuroanatomic Terms Whose Prosomeric Definition Conflicts With Columnar Tradition. Front Neuroanat. 2019 Feb;13:20

Raghanti MA, Munger EA, Wicinski B, Butti C, Jacobs B, Hof PR. Comparative structure of the cerebral cortex in large mammals. In: Kaas $\mathrm{JH}$, editor. Evolution of Nervous Systems. Volume 4. Elsevier; 2017. pp. 267-89.

Reiner A, Hart NM, Lei W, Deng Y. Corticostriatal projection neurons - dichotomous types and dichotomous functions. Front Neuroanat. 2010 Oct; $4: 142$

Robertson B, Huerta-Ocampo I, Ericsson J, Stephenson-Jones M, Pérez-Fernández J, Bolam JP, et al. The dopamine D2 receptor gene in lamprey, its expression in the striatum and cellular effects of D2 receptor activation. PLoS One. 2012;7(4):e35642.
Ryczko D, Dubuc R. Dopamine and the Brainstem Locomotor Networks: From Lamprey to Human. Front Neurosci. 2017a May;11:295.

Ryczko D, Grätsch S, Alpert MH, Cone JJ, Kasemir J, Ruthe A, et al. Descending Dopaminergic Inputs to Reticulospinal Neurons Promote Locomotor Movements. J Neurosci. 2020 Oct;40(44):8478-90.

Ryczko D, Grätsch S, Auclair F, Dubé C, Bergeron $\mathrm{S}$, Alpert $\mathrm{MH}$, et al. Forebrain dopamine neurons project down to a brainstem region controlling locomotion. Proc Natl Acad Sci USA. 2013 Aug;110(34):E3235-42.

Ryczko D, Grätsch S, Schläger L, Keuyalian A, Boukhatem Z, Garcia C, et al. Nigral Glutamatergic Neurons Control the Speed of Locomotion. J Neurosci. 2017b Oct;37(40):975970.

Schotland J, Shupliakov O, Wikström M, Brodin L, Srinivasan M, You ZB, et al. Control of lamprey locomotor neurons by colocalized monoamine transmitters. Nature. 1995 Mar; 374(6519):266-8

Shepherd GM. Synaptic organization of the mammalian olfactory bulb. Physiol Rev. 1972 Oct; 52(4):864-917.

Shepherd GM. The human sense of smell: are we better than we think? PLoS Biol. 2004 May; 2(5):E146.

Shepherd GM. The microcircuit concept applied to cortical evolution: from three-layer to sixlayer cortex. Front Neuroanat. 2011 May;5:30.

Sherman SM, Guillery RW. Functional organization of thalamocortical relays. J Neurophysiol. 1996 Sep;76(3):1367-95.

Sherman SM. Thalamus plays a central role in ongoing cortical functioning. Nat Neurosci. 2016 Apr;19(4):533-41.

Smeets WJ, Marín O, González A. Evolution of the basal ganglia: new perspectives through a comparative approach. J Anat. 2000 May; 196(Pt 4):501-17.

Stephenson-Jones M, Ericsson J, Robertson B, Grillner S. Evolution of the basal ganglia: dual-output pathways conserved throughout vertebrate phylogeny. J Comp Neurol. 2012a Sep;520(13):2957-73.

Stephenson-Jones M, Floros O, Robertson B, Grillner S. Evolutionary conservation of the habenular nuclei and their circuitry controlling the dopamine and 5-hydroxytryptophan (5-HT) systems. Proc Natl Acad Sci USA. 2012b Jan;109(3):E164-73.

Stephenson-Jones M, Kardamakis AA, Robertson $\mathrm{B}$, Grillner S. Independent circuits in the basal ganglia for the evaluation and selection of actions. Proc Natl Acad Sci USA. 2013 Sep;110(38):E3670-9.

Stephenson-Jones M, Samuelsson E, Ericsson J, Robertson B, Grillner S. Evolutionary conservation of the basal ganglia as a common vertebrate mechanism for action selection. Curr Biol. 2011 Jul;21(13):1081-91.

Stephenson-Jones M, Yu K, Ahrens S, Tucciarone JM, van Huijstee AN, Mejia LA, et al. A basal ganglia circuit for evaluating action outcomes. Nature. 2016 Nov;539(7628):289-93. 
Suárez R, Gobius I, Richards LJ. Evolution and development of interhemispheric connections in the vertebrate forebrain. Front Hum Neurosci. 2014 Jul;8:497.

Subramanian HH, Balnave RJ, Holstege G. Microstimulation in Different Parts of the Periaqueductal Gray Generates Different Types of Vocalizations in the Cat. J Voice. 2020 Mar;S0892-1997(19)30589-2.

Sugahara F, Murakami Y, Pascual-Anaya J, Kuratani S. Reconstructing the ancestral vertebrate brain. Dev Growth Differ. 2017 May; 59(4):163-74.

Sugahara F, Pascual-Anaya J, Oisi Y, Kuraku S, Aota S, Adachi N, et al. Evidence from cyclostomes for complex regionalization of the ancestral vertebrate brain. Nature. 2016 Mar; 531(7592):97-100.

Suryanarayana SM, Pérez-Fernández J, Robertson B, Grillner S. Olfaction in Lamprey Pallium Revisited-Dual Projections of Mitral and Tufted Cells. Cell Rep. 2021 Jan;34(1):108596.

Suryanarayana SM, Pérez-Fernández J, Robertson B, Grillner S. The evolutionary origin of visual and somatosensory representation in the vertebrate pallium. Nat Ecol Evol. 2020 Apr;4(4):639-51.

Suryanarayana SM, Robertson B, Wallén P, Grillner S. The Lamprey Pallium Provides a Blueprint of the Mammalian Layered Cortex. Curr Biol. 2017 Nov;27(21):3264-3277.e5.
Suryanarayana SM. On the evolutionary origin of the vertebrate cortex. Doctoral dissertation, Karolinska Institutet. 2019.

Suzuki DG, Pérez-Fernández J, Wibble T, Kardamakis AA, Grillner S. The role of the optic tectum for visually evoked orienting and evasive movements. Proc Natl Acad Sci USA. 2019 Jul;116(30):15272-81.

Tasic B, Yao Z, Graybuck LT, Smith KA, Nguyen TN, Bertagnolli D, et al. Shared and distinct transcriptomic cell types across neocortical areas. Nature. 2018 Nov;563(7729):72-8.

Thompson RH, Ménard A, Pombal M, Grillner S. Forebrain dopamine depletion impairs motor behavior in lamprey. Eur J Neurosci. 2008 Mar;27(6):1452-60.

Tosches MA, Laurent G. Evolution of neuronal identity in the cerebral cortex. Curr Opin Neurobiol. 2019 Jun;56:199-208.

Tosches MA, Yamawaki TM, Naumann RK, Jacobi AA, Tushev G, Laurent G. Evolution of pallium, hippocampus, and cortical cell types revealed by single-cell transcriptomics in reptiles. Science. 2018 May;360(6391):881-8.

Ulinski PS. The cerebral cortex of reptiles. In: Jones EG, Peters A, editors. Cerebral Cortex. New York: Plenum; 1990. pp. 139-216.

Ulinski PS. Ultrastructure of the dorsal lateral geniculate complex in turtles of the genera Pseudemys and Chrysemys. Brain Behav Evol. 1986;29(3-4):117-42.
Villar-Cerviño V, Barreiro-Iglesias A, Mazan S, Rodicio MC, Anadón R. Glutamatergic neuronal populations in the forebrain of the sea lamprey, Petromyzon marinus: an in situ hybridization and immunocytochemical study. J Comp Neurol. 2011 Jun;519(9):1712-35.

von Twickel A, Kowatschew D, Saltürk M, Schauer M, Robertson B, Korsching S, et al. Individual Dopaminergic Neurons of Lamprey SNc/VTA Project to Both the Striatum and Optic Tectum but Restrict Co-release of Glutamate to Striatum Only. Curr Biol. 2019 Feb;29(4):677-685.e6.

Watson C, Puelles L. Developmental gene expression in the mouse clarifies the organization of the claustrum and related endopiriform nuclei. J Comp Neurol. 2017 Apr;525(6):1499-508.

Wicht H, Northcutt RG. Telencephalic connections in the Pacific hagfish (Eptatretus stouti), with special reference to the thalamopallial system. J Comp Neurol. 1998 Jun;395(2):245-60.

Wullimann MF, Umeasalugo KE. Sonic hedgehog expression in zebrafish forebrain identifies the teleostean pallidal signaling center and shows preglomerular complex and posterior tubercular dopamine cells to arise from shh cells. J Comp Neurol. 2020 Jun;528(8):1321-48.

Wullimann MF. Ancestry of basal ganglia circuits: new evidence in teleosts. J Comp Neurol. 2014 Jun;522(9):2013-8. 